\title{
The social capital impact on the effectiveness of university departments
}

\author{
Elena Agapova, Marina Zharova, Irina Gushchina*, Ekaterina Ivanova, and Natalia \\ Kravtsova \\ Herzen State Pedagogical University of Russia, 191186, Moika Emb., 48, St. Petersburg, Russia
}

\begin{abstract}
The article presents the results of assessing the level of social capital of a university department, the mutual influence of the type of organizational culture and the effectiveness of its work. In the course of the study, the concept of social capital was generalized and refined in the context of the concept of sustainable education, as well as in relation to an educational institution, to the community of a higher educational organization. There were tested the ideas of N.P. Makarkin and O.B. Tomilina about the impact of organizational culture on the efficiency of the university. To ensure the comparison of the different departments data with each other there was proposed a method for bringing to a single scale of assessments and calculating weighted average indicators, which made it possible to derive a single integral assessment of the social capital of a department/unit.
\end{abstract}

\section{Introduction}

The university effectiveness is determined by many factors, but researchers highlight the role of such 'pressure groups' as subjects of education. It is no coincidence that there are the performance indicators of teachers and research teams in the range of monitoring objects of the university, since the growth of their interest, activity and involvement in solving various kinds of problems depends on their competence, motivation, creativity. The relationship specifics between university employees, their constructiveness, positivism, mutual trust, social media resources are the most important social factors influencing the competitiveness of the university.

At the same time, there are practically no applied studies of this phenomenon in the field of higher education: the concept of social capital has not received sufficient scientific understanding, the influence of organizational culture on the efficiency of departments, no correlations have been revealed between the social capital index and the actual indicators of the effectiveness of departments. In this connection it is necessary to develop a research methodology, to create a model of determination the relationship of higher education entities in various aspects of social reality, as well as their dynamics.

The incorporation of social capital into the university management system based on the harmonization of the individual goals of teachers and research teams, the harmonization of

\footnotetext{
${ }^{*}$ Corresponding author: i.sychevaaa@gmail.com
} 
both informal interpersonal and formal, hierarchically organized relations, can not only contribute to the process of building up human capital, but also ensure social synergy in achieving the goals of the university, which resonates with the concept of sustainable education. On the contrary, insufficient use of the social capital model in university management can increase the degree of formalization of professional activity and dissociation of social practices of educational subjects.

Thus, the defined goal: to evaluate the social capital impact on the level of effectiveness of the university departments, the relationship of the social capital level, such as organizational culture and performance.

\section{Materials and Methods}

\subsection{Theoretical framework}

The study was based on the concept of social capital created by J. Coleman, J. Hanifan, R. Putnam, P. Bourdieu, F. Fukuyama and others [5-14]. As a result of theoretical generalization, the concept of "social capital" has been clarified in relation to an institution of higher education - this is the relationship of employees, based on the commonality of norms and values, trust and reciprocal exchange in the social space of the university in department, faculty, and university level.

The work is based on data from a study conducted in 2012 by A.G. Bodunkova and I.P. Chernaya [2], who proposed using social capital as an indicator of the level of development of entrepreneurial culture in a university. Also there had been tested the idea (2004) by N.P. Makarkin and O.B. Tomilin [3] about the influence of organizational culture on the efficiency of the university, namely: the rhomboidal form of the culture profile ensures the efficiency of the organization, since in this case there is an opportunity for a positive contribution of all alternative types of cultures.

The analysis of theoretical sources on the research problem revealed a shortage of social capital. The dual nature of social capital implies the relationship and interaction of its "individual" and "social" forms; however, researchers have noted the presence of contradictions: the accumulation of "individual" social capital prevents the accumulation of "public."

This is facilitated by: lack of social capital of university teachers; insufficient demand for the social capital of teachers by management structures; low level of interdepartmental and interfaculty interaction; low demand for research and development activities; weak integration of universities into the real sector of the economy, university networks, world science; formalism in solving strategic problems of the university development.

An additional problem is the complexity of the operational description of the structural elements of social capital, such as, for example, "community", "network", "connections", etc. Another problem in the empirical study of the social capital of a university is its multidimensionality.

\subsection{Research methodology}

The study was conducted at the Institute of Economics and Management of the Herzen State Pedagogical University of Russia (St. Petersburg).

In order to measure the social capital level of the teaching staff of the departments and the institute as a whole, two questionnaires were developed. The research was carried out in the following general directions: 1) the level of employee confidence and 2) the degree of development of the employee's connections. 
To provide a comparison of data from different departments with each other there has been proposed a method of reduction to a single grading scale and calculation of weighted averages, which allowed bringing a single integrated assessment of social capital division. In order to analyze the impact of organizational culture on the level of social capital departments according to the procedure of K. Cameron and R. Quinn there was conducted the survey among employees to identify basic types of organizational culture. The research is aimed at a thorough study of the designated areas in order to identify levels, connections, and explain the identified patterns. The interpretation of the research results was made in the form of an impartial analysis based on value neutrality.

\section{Results and Discussion}

According to the survey were carried out calculations of indices of trust and professional and social importance (taking into account the number and strength of the connections), and estimated the total value of the social capital of the department (Table №1), comparison with the data efficiency of the units, as reflected in the rating.

The purposes of this research interest is to determine correlations between social capital index and the actual performance of the department (according to the effective contract). In the framework of the pilot study, a private indicator of the publication activity of teachers was chosen as the performance indicators. Further, an attempt was made to identify correlations between the index of professional and social importance and the actual indicators of the effectiveness of teachers' activities.

By calculating the linear correlation coefficient, the following hypothesis was tested: a teacher's publication activity depends on the number of his positive connections with the professional community. The correlation coefficient turned out to be less than 0.26 , which indicates the absence of the alleged relationship, therefore, the initial hypothesis was not confirmed. The index of the professional and social significance of a particular teacher was calculated as a multiplicative convolution of his incoming and outgoing positive connections within the institution and a balanced assessment of external connections, including: frequent direct contacts with the management of the institution; direct contacts at the university level; direct contacts with the professional community outside the university; direct contacts with employers.

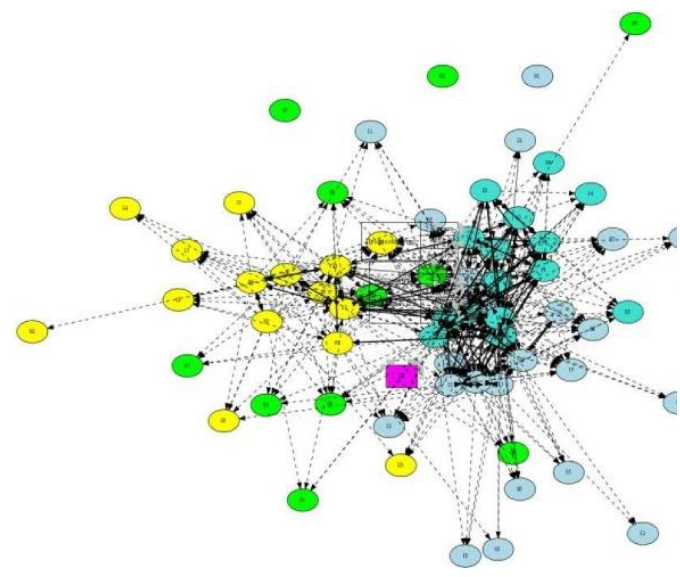

Fig. 1. Visualization of professional and social relations based on SFDP method without grouping of departments and the reduction of the text node

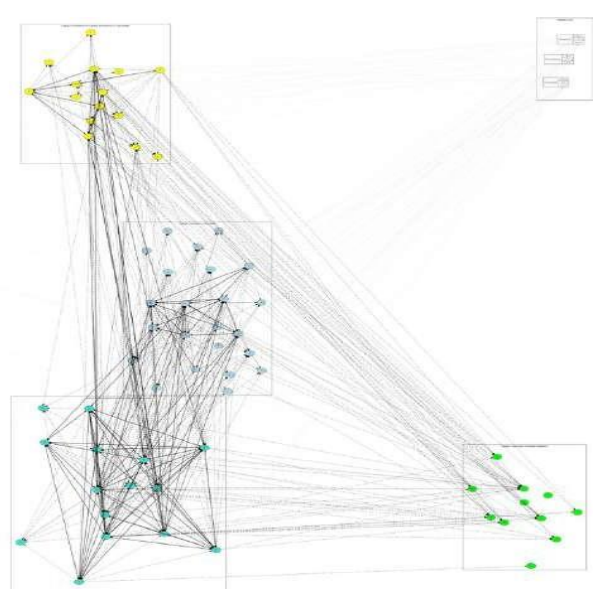

Fig. 2. Visualization of professional and social relations based on FDP method grouped by departments and the reduction of the text node 
Analysis of the survey results revealed individual and group "centers of gravity". To visualize the structure of professional and social ties, the Gephi program was used, as well as some methods of the Graphviz software package (fig.1 and 2).

After calculating the individual indices of the professional and social significance of the respondents, the total values of this index for the departments were calculated, forming the values of the indicator "Professional and social significance of the department", which, together with the group trust indices, can be determined as the integral value of the social capital of the department. In exactly the same way as in the case of group confidence indices, an assessment was made of the relationship between the indices of professional and social significance and performance indicators.

Table 1. Summary table of the resulting values of social capital and the departments effectiveness

\begin{tabular}{|c|c|c|c|c|c|}
\hline \multirow{2}{*}{ Code } & \multirow{2}{*}{ Index } & \multicolumn{4}{|c|}{ Department } \\
\hline & & №1 & №2 & №3 & №4 \\
\hline CTI & $\begin{array}{l}\text { Collective Trust Index }= \\
\left(\mathrm{T} 1+\mathrm{T} 2+\mathrm{T} 3+\mathrm{T} 4+\mathrm{T} 5+\mathrm{T} 5{ }^{\prime}+\mathrm{T} 6\right) / 7\end{array}$ & 5.41 & 5.53 & 5.69 & 5.81 \\
\hline IPSID & $\begin{array}{l}\text { Index of professional and social } \\
\text { importance of the department }= \\
(\mathrm{C} 1+\mathrm{C} 2+\mathrm{C} 3+\mathrm{C} 4+\mathrm{C} 5+\mathrm{C} 6+\mathrm{C} 7+\mathrm{C} 8) / 8 \\
\end{array}$ & 4.81 & 3.89 & 3.13 & 0.78 \\
\hline $\mathrm{SC}$ & Total SC department $=($ IPSID + CTI $) / 2$ & 5.11 & 4.71 & 4.41 & 3.29 \\
\hline & Position in the ranking of the institute & 1 & 2 & 3 & 4 \\
\hline
\end{tabular}

The rating data clearly show the direct dependence of the efficiency of the structural unit on the level of development of the social capital of the unit / department.

Qualification organizational culture showed that the chair with clan organizational culture and general organizational profile tending to rhomboidal form (Fig. 3), and has the largest social capital and greatest efficiency.

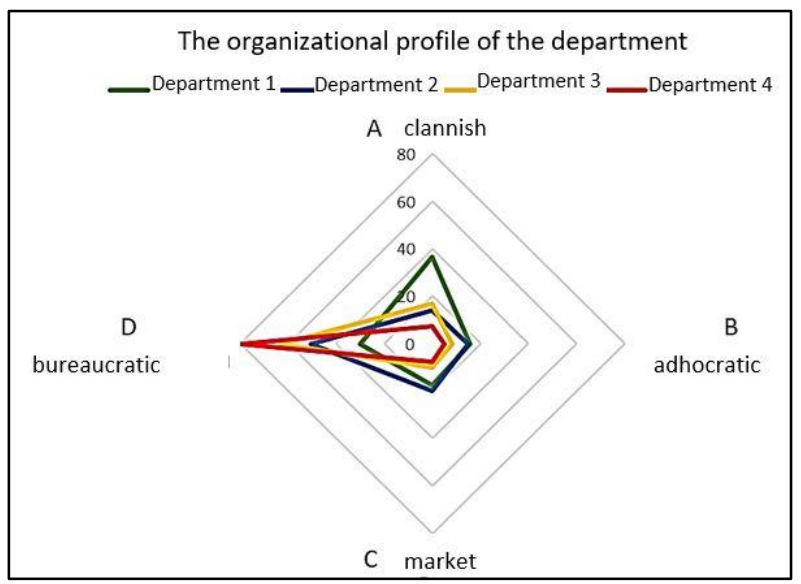

Fig. 3. Organizational profile of departments

For the research departments there is a general tendency towards a hierarchical or bureaucratic type of organizational culture. This is especially true for ineffective university departments. At the same time, the assumption was confirmed that with the predominance of one culture in the system (institution), in the subsystems (departments), an emphasis on others is possible. Thus, in the leading Department No. 1, clannish culture prevails over 
bureaucratic one. It was confirmed that the level of organizational culture affects the ability of the unit to accumulate social capital, which in turn affects the efficiency of its work.

\section{Conclusion}

The structure of the social capital of the teaching staff is very heterogeneous and diverse, in addition to internal interactions and influence on the efficiency of processes in the university, the teacher is included in various external networks and groups, acting as an element of the social capital of external actors: students, graduates, employers, expert communities, and other stakeholders, significantly influencing the effectiveness of their activities. The study of the influence of social capital on the professional activity of university teachers requires an analysis of a sufficiently large number of factors, which requires the development of special mathematical models.

\subsection{Indirect conclusions}

1. The study revealed low level of interest and activity of faculty members to participate in such events. By the nature of his activity, the teacher himself is both a role model and a "co-author" of building the social capital of external actors.

2. An indirect confirmation of a sufficiently high level of attributive trust of the teaching staff can be the openness of the respondents - only $10 \%$ of the respondents used the opportunity of anonymous answer.

3. Work on building up social capital is not self-organizing and requires the use of management methods. This circumstance presupposes both the development of organizational and motivational measures and the use of special mathematical tools for constructing confidence intervals.

\subsection{Immediate conclusions}

1. A pilot study has shown that a department with a clannish organizational culture and a general organizational profile tending to a rhomboid shape has both the greatest social capital and the greatest efficiency.

2. The study revealed a general tendency towards a decrease in the level of trust at the levels of the organizational hierarchy from the leadership of the department to the leadership of the university. At the same time, the data obtained indicate that the strongest negative influence on the group effectiveness of teaching staff is exerted by a low index of trust in the leadership of the department.

3. When analyzing correlations for a set of factors, dependencies were identified that require additional research and interpretation, in particular, the relationship between the tightness of intradepartmental and interdepartmental relations, the relationship between the level of trust in the university leadership and the number of positive incoming connections, between the level of trust in the university leadership and the intensity of contacts with employers and etc.

4. A particular hypothesis about the dependence of the effectiveness of scientific activity (in particular, the number of citations) with the value of positive incoming and outgoing connections was not confirmed, which refutes the conventional opinion that the Hirsch index can be artificially increased due to the agreement of teachers about mutual citation of each other. At the same time, the strong positive correlation of the h-index of respondents with the level of their willingness to participate in joint educational programs 
and scientific research with colleagues, revealed in the study, requires understanding and explanation.

Further development of the work is expected in the following directions:

1. Increase in the number of the studied factors that form social capital and determination of their weight.

2. Increasing the reliability and validity of the data obtained by expanding the sample, developing adequate mathematical models and using special data processing tools. Analysis of the sources of social capital formation and management capabilities for managing the processes of its accumulation and use to increase organizational efficiency in order to implement the concept of sustainable education.

\section{Acknowledgements}

The reported study was funded by RFBR, projects number 18-013-00646 \18 and 20-31390009.

\section{References}

1. E.A. Balezina, D.A. Bulgakova, A.S. Deryugin, Theory, methodology and methods of empirical research of social problems (2016)

2. A.G. Bodunkova, I.P. Chernaya, Vestnik of Pushkin Leningrad State University, 4 (2012)

3. N.P. Makarkin, O.B. Tomilin, A.V. Britov, University management: practice and analysis, 5-6 (33) (2004)

4. I.B. Olimpieva, A.A. Kondakov, L.V. Yezhova, A.L. Slobodskoy, Petersburg sociology today. Collection of scientific works of the Sociological Institute of the Russian Academy of Sciences, 5 (2014)

5. Bourdieu P., Handbook of theory and research for the sociology of education (1986)

6. Bourdieu P., The Logic of Practice (1990)

7. Campbell C, Wood R, Kelly M., Social Capital and Health (1999)

8. Coleman J., Foundations of social theory (1990)

9. Coleman James S., The American Journal of Sociology, 94 (1998)

10. Fukuyama F., Culture matters: How values shape human progress (2000)

11. Fukuyama F., Social capital and development: The coming agenda, 22 (1) (2002)

12. Hanifan L.J., The Community Center (1920)

13. Hanifan L.J., Annals of the American Academy of Political and Social Science (1967)

14. Putnam R.D., Canadian Journal of Policy Research, 2 (2001) 